\title{
Effect of Magnetic Field Annealing on Microstructure and Magnetic Properties of FeCuNbSiB Nanocrystalline Magnetic Core with High Inductance
}

\author{
Xingdu Fan, Fangliang Zhu, Qianqian Wang, Mufeng Jiang ${ }^{1}$, Baolong Shen* \\ School of Materials Science and Engineering, Southeast University, Nanjing 211189, China \\ ${ }^{1}$ Londerful New Material Technology Corp., Nantong 226233, China
}

*Correspondence to:

Shen $\mathrm{BL}$

Tel: +86-25-52091077

Fax: +86-25-52091077

E-mail: blshen@seu.edu.cn

Received December 12, 2016

Revised December 22, 2016

Accepted December 22, 2016
Transverse magnetic field annealing (TFA) was carried out on $\mathrm{Fe}_{73.5} \mathrm{Cu}_{1} \mathrm{Nb}_{3} \mathrm{Si}_{15.5} \mathrm{~B}_{7}$ nanocrystalline magnetic core with the aim at decreasing coercivity $\left(H_{\mathrm{c}}\right)$ while keeping high inductance $\left(L_{\mathrm{s}}\right)$. The magnetic field generated by direct current (DC) was applied on the magnetic core during different selected annealing stages and it was proved that the nanocrystalline magnetic core achieved lowest $H_{c}$ when applying transverse field during the whole annealing process (TFA1). Although the microstructure and crystallization degree of the nanocrystalline magnetic core exhibited no obvious difference after TFA1 compared to no field annealing, the TFA1 sample showed a more uniform nanostructure with a smaller mean square deviation of grain size distribution. $H_{c}$ of the nanocrystalline magnetic core annealed under TFA1 decreased along with the increasing magnetic field. As a result, the certain size nanocrystalline magnetic core with low $H_{c}$ of $0.6 \mathrm{~A} / \mathrm{m}$, low core loss $(W$ at 20 $\mathrm{kHz}$ ) of $1.6 \mathrm{~W} / \mathrm{kg}$ under flux density of $0.2 \mathrm{~T}$ and high $L_{\mathrm{s}}$ of $13.8 \mu \mathrm{H}$ were obtained after TFA1 with the DC intensity of $140 \mathrm{~A}$. The combination of high $L_{\mathrm{s}}$ with excellent magnetic properties promised this nanocrystalline alloy an outstanding economical application in high frequency transformers.

Key Words: Nanocrystalline alloy, Transverse magnetic field annealing, Induced magnetic anisotropy, Magnetic property, Inductance

\section{INTRODUCTION}

Since the nanocrystalline $\mathrm{Fe}_{73.5} \mathrm{Si}_{13.5} \mathrm{~B}_{9} \mathrm{Nb}_{3} \mathrm{Cu}_{1}$ alloy was first found by Yoshizawa in 1988, nanocrystalline soft magnetic alloys (Makino, 2012; Ohta \& Yoshizawa, 2008; Suzuki et al., 1991a, 1991b; Willard et al., 1998) have attracted great attention due to their excellent soft magnetic properties such as high saturation magnetic flux density $\left(B_{\mathrm{s}}\right)$, high initial permeability $\left(\mu_{\mathrm{i}}\right)$, low coercivity $\left(H_{\mathrm{c}}\right)$ and low core loss $(P)$. From then on, three typical nanocrystalline alloy systems have been developed under the trade name of Finemet (Hitachi Matels Ltd., Japan) (Yoshizawa et al., 1988), Nanoperm (MH\&W International Corp., USA) (Suzuki et al., 1991a, 1991b) and Hitperm (Carnegie Mellon University, USA)
(Willard et al., 1998). Among these alloys, Nanoperm exhibits high $B_{\mathrm{s}}$ of 1.5 1.7 T but contains expensive and easily oxidized elements (e.g. $\mathrm{Zr}$ or Hf). Hitperm possesses high Curie temperature but the $H_{c}$ is up to $200 \mathrm{~A} / \mathrm{m}$ and the large amount of additive element $\mathrm{Co}$ increases material cost. Compared to the above alloys, Finemet exhibits high $\mu_{\mathrm{i}}$ of 100,000 , low $H_{c}$ of $0.53 \mathrm{~A} / \mathrm{m}$, as well as convenient production process, thus has been widely applied in electronic components such as transformers, inductors, sensors, filters etc.

The soft magnetic properties of nanocrystalline alloys result from the uniform nanocrystal structure which effectively reduces the magneto-crystalline anisotropy (Herzer, 1990, 1992, 1997, 2005, 2013). In addition, it has been pointed out that magnetic field annealing can further optimize soft

(a) This is an open-access article distributed under the terms of the Creative Commons Attribution Non-Commercial License (http://creativecommons.org/licenses/by-nc/4.0) which permits unrestricted noncommercial use, distribution, and reproduction in any medium, provided the original work is properly cited.

Copyrights @ 2017 by Korean Society of Microscopy 
magnetic properties because the uniaxial anisotropy $\left(K_{\mathrm{u}}\right)$ induced by magnetic field has been utilized for tailoring the shape of hysteresis loops (Herzer, 1997, 2005, 2013; Ito et al, 2007; Suzuki \& Herzer, 2012). The excellent soft magnetic properties of nanocrystalline alloy, such as low $H_{c}$ and low core loss $(W)$, contribute to energy conservation and environmental protection. On the other hand, inductance $\left(L_{\mathrm{s}}\right)$ is also an important parameter of nanocrystalline magnetic core for electronic components application. With larger $L_{s}$, the nanocrystalline magnetic core is more sensitive and effective impedance to the alternating current (AC) interference signal, which is more beneficial to application in signal screening, noise filtering and current stabilizing. However, there are few reports about the influence of magnetic field annealing conditions on magnetic properties of nanocrystalline magnetic core with high inductance. Thus, in this work, we investigated the magnetic properties variation for a certain size magnetic core under no field annealing (NFA) and transverse magnetic field annealing (TFA), respectively, with an essential prerequisite of obtaining or keeping high inductance. The relationship between microstructure and magnetic properties under TFA and NFA were also investigated.

\section{MATERIALS AND METHODS}

Amorphous ribbons with nominal composition of $\mathrm{Fe}_{73.5} \mathrm{Cu}_{1} \mathrm{Nb}_{3} \mathrm{Si}_{15.5} \mathrm{~B}_{7}$ were prepared by single roller melt spinning. The width and thickness were $10 \mathrm{~mm}$ and $20 \mu \mathrm{m}$, respectively. Thermal stability was evaluated by differential scanning calorimeter (DSC) under a flowing highly purified argon atmosphere with a heating rate of $0.67^{\circ} \mathrm{C} / \mathrm{s}$. Melt-spun ribbons were coiled into toroidal core with $20 \mathrm{~mm}$ outer diameter and $14 \mathrm{~mm}$ inner diameter. Toroidal core samples were annealed under vacuum to develop nanocrystalline structure by transverse magnetic field furnace and the magnetic field was adjusted by current intensity. The core samples were placed in furnace chamber to ensure magnetic field direction parallel to the width of ribbon. Microstructure of annealed samples was identified by X-ray diffraction (XRD) with $\mathrm{Cu} \mathrm{K \alpha}$ radiation and transmission electron microscopy (TEM). Grain size was measured by Nano Measurer software (Fudan University, China) for statistical analysis. $L_{\mathrm{s}}$ was measured at a high frequency of $100 \mathrm{kHz}$ and voltage 0.3 $\mathrm{V}$ by inductance-capacitance-resistance digital bridge. $B_{s}$ was measured by a vibrating sample magnetometer under a maximum applied field of $800 \mathrm{kA} / \mathrm{m} . H_{\mathrm{c}}$ and maximum permeability $\left(\mu_{\mathrm{m}}\right)$ were measured by DC $B-H$ loop tracer under a maximum applied field of $800 \mathrm{~A} / \mathrm{m}$. Core loss was measured using AC $\mathrm{B}-H$ analyzer. The value of inductance and magnetic properties were calculated by averaging three samples annealed in the same condition.

The industrial annealing process for nanocrystalline magnetic core included five stages: I) heat the furnace from room temperature to $330^{\circ} \mathrm{C}$; II) keep the furnace temperature at $330^{\circ} \mathrm{C}$ for $60 \mathrm{~min}$, then heat the furnace to $480^{\circ} \mathrm{C}$; III) keep the furnace temperature at $480^{\circ} \mathrm{C}$ for $60 \mathrm{~min}$, then heat the furnace to annealing temperature $\left(T_{\mathrm{a}}\right)$; IV) keep the furnace temperature at selected $T_{\mathrm{a}}$ for $60 \mathrm{~min} ; \mathrm{V}$ ) cool down to room temperature with a cooling rate about $0.167^{\circ} \mathrm{C} / \mathrm{s}$. In this study, we developed the TFA process based on the industrial annealing technology by adding transverse field through different annealing stages. Four TFA conditions were carried out, named TFA1, TFA2, TFA3 and TFA4, respectively. TFA1: applying transverse field through annealing stages II, III, IV and V; TFA2: applying transverse field through annealing stages III, IV and V; TFA3: applying transverse field through annealing stages IV and V; TFA4: applying transverse field only through annealing stage $\mathrm{V}$.

\section{RESULTS AND DISCUSSION}

In order to investigate the crystallization behavior, isothermal crystallization annealing was performed on $\mathrm{Fe}_{73.5} \mathrm{Cu}_{1} \mathrm{Nb}_{3} \mathrm{Si}_{15.5} \mathrm{~B}_{7}$ amorphous ribbon samples at different temperature. Fig. 1 shows XRD patterns of ribbon samples annealed for $10 \mathrm{~min}$ at $480^{\circ} \mathrm{C}, 550^{\circ} \mathrm{C}, 710^{\circ} \mathrm{C}$, which are the temperatures lower than the first crystallization temperature $T_{\mathrm{x} 1}$, between $T_{\mathrm{x} 1}$ and the first crystallization peak temperature $T_{\mathrm{p} 1}$, just higher than the second crystallization temperature $T_{\mathrm{x} 2}$, respectively, as shown on the DSC curve in the insert. The XRD pattern of as-quenched ribbon is also shown for comparison. It is seen from the XRD patterns that the $\alpha-\mathrm{Fe}(\mathrm{Si})$ nanocrystals precipitated in the amorphous matrix after annealed at $480^{\circ} \mathrm{C}$, but the grain size is too tiny and the volume fraction is too small that only one diffraction peak is detected, which suggests the grain just start to nucleate from

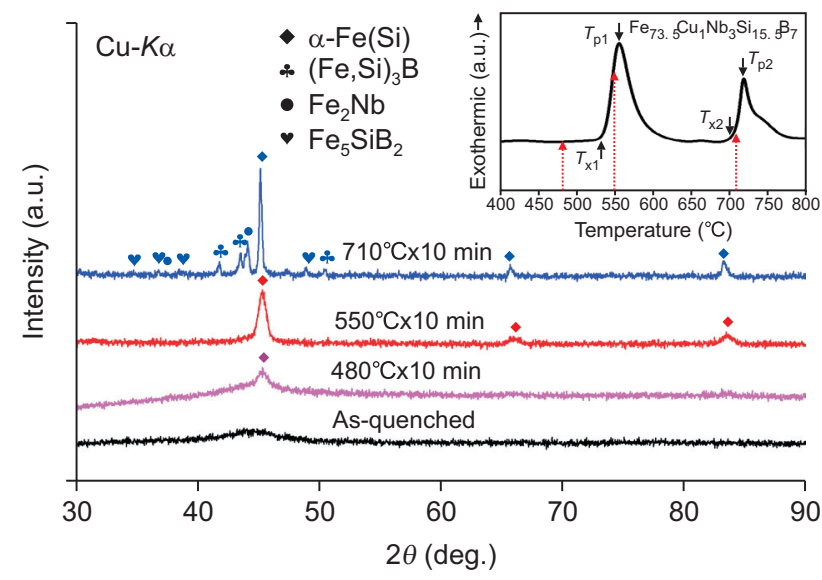

Fig. 1. The X-ray diffraction patterns of ribbon samples annealed for 10 min at $480^{\circ} \mathrm{C}, 550^{\circ} \mathrm{C}$, and $710^{\circ} \mathrm{C}$ with as-quenched ribbon was showed for comparison. The insert is differential scanning calorimeter curve of $\mathrm{Fe}_{73.5} \mathrm{Cu}_{1} \mathrm{Nb}_{3} \mathrm{Si}_{15.5} \mathrm{~B}_{7}$ melt-spun ribbons. a.u., arbitrary unit; deg., degree. 
the amorphous matrix. Three characteristic diffraction peaks of $\alpha-\mathrm{Fe}(\mathrm{Si})$ can be identified clearly after annealed at $550^{\circ} \mathrm{C}$ which is extremely close to $T_{\mathrm{x} 1}$. In contrast, after annealed at $710^{\circ} \mathrm{C}$ for $10 \mathrm{~min}$, several Fe-B, Fe-Nb compounds, such as $(\mathrm{Fe}, \mathrm{Si})_{3} \mathrm{~B}, \mathrm{Fe}_{2} \mathrm{Nb}$ and $\mathrm{Fe}_{5} \mathrm{SiB}_{2}$, precipitated and deteriorated soft magnetic property. So it is confirmed that $T_{\mathrm{x} 1}$ corresponds to the precipitation temperature of single $\alpha-\mathrm{Fe}(\mathrm{Si})$ soft magnetic phase and $T_{\mathrm{x} 2}$ is the crystallization temperature of $(\mathrm{Fe}, \mathrm{Si})_{3} \mathrm{~B}, \mathrm{Fe}_{2} \mathrm{Nb}$ and $\mathrm{Fe}_{5} \mathrm{SiB}_{2}$. The difference between $T_{\mathrm{x} 1}$ and $T_{x 2}$ is $170^{\circ} \mathrm{C}$, reflecting the alloy exhibits a preferable thermal stability, which is advantageous for developing nanocrystalline alloys, as it is reported that a wide crystallization temperature difference is beneficial for the precipitation of nanocrystals

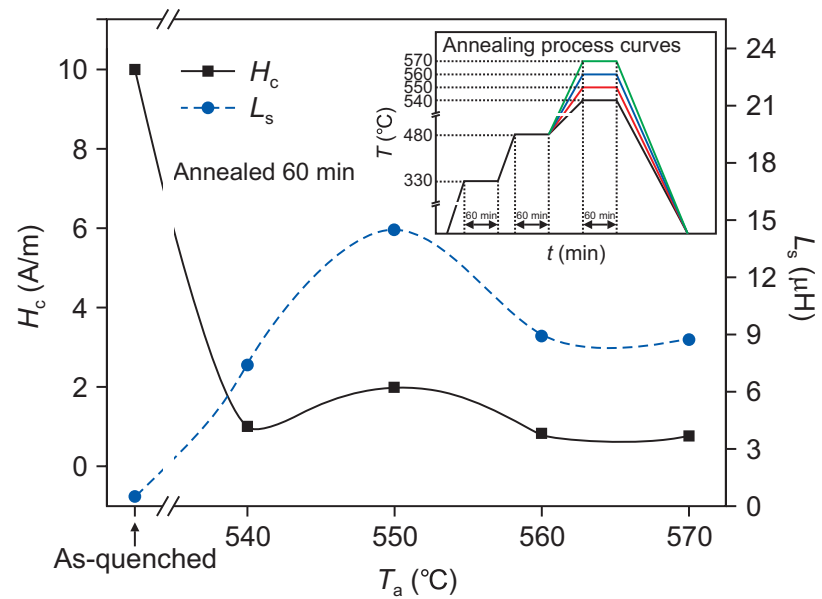

Fig. 2. The dependence of inductance $\left(L_{\mathrm{s}}\right)$ and coercivity $\left(H_{\mathrm{c}}\right)$ on annealing temperature $\left(T_{\mathrm{a}}\right)$ for $\mathrm{Fe}_{73.5} \mathrm{Cu}_{1} \mathrm{Nb}_{3} \mathrm{Si}_{15.5} \mathrm{~B}_{7}$ nanocrystalline magnetic core under isothermal annealing condition compared with no annealing condition sample. The insert is annealing process curves with different $T_{\mathrm{a}}$ $\left(540^{\circ} \mathrm{C}, 550^{\circ} \mathrm{C}, 560^{\circ} \mathrm{C}\right.$, and $\left.570^{\circ} \mathrm{C}\right)$ in industrial production.

A

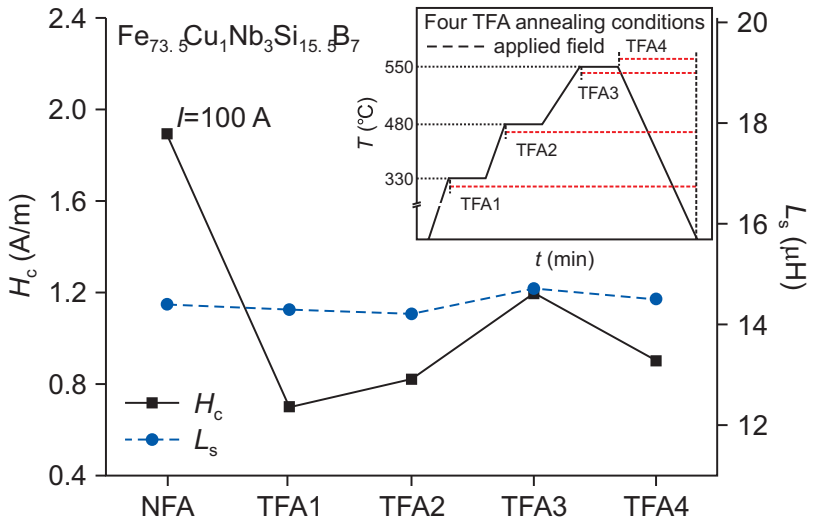

with uniform structure, which can improve the soft magnetic properties (Fan et al., 2013; Makino et al., 1995). Combining the crystallization behavior research results with the industrial manufacturing conditions, the annealing temperature $\left(T_{\mathrm{a}}\right)$ in this study are selected as $540^{\circ} \mathrm{C}, 550^{\circ} \mathrm{C}, 560^{\circ} \mathrm{C}$, and $570^{\circ} \mathrm{C}$, respectively, at which the precipitation of $\alpha-\mathrm{Fe}(\mathrm{Si})$ is promoted while the precipitation of hard magnetic phases is inhibited (Hono et al., 1999). The annealing time is fixed as 60 minutes for fully crystallization in order to obtain an ultrafine nanocrystalline structure (Yoshizawa \& Yamauchi, 1990).

Fig. 2 shows the dependence of $L_{\mathrm{s}}$ and $H_{\mathrm{c}}$ of nanocrystalline magnetic core samples on $T_{\mathrm{a}}$ under different isothermal annealing conditions. The value of as-quenched alloy is also shown for comparison. The isothermal annealing process, as sketched in the insert in Fig. 2, was designed based on the industrial annealing technology described in the experimental procedures, including five stages: I) heat the furnace from room temperature to $330^{\circ} \mathrm{C}$, which is far below $T_{\mathrm{x} 1}$; II) keep the furnace temperature at $330^{\circ} \mathrm{C}$ for $60 \mathrm{~min}$ to ensure heat uniformity in furnace, then heat the furnace to $480^{\circ} \mathrm{C}$; III) preserve the furnace temperature at $480^{\circ} \mathrm{C}$ for $60 \mathrm{~min}$, which not only keeps inner and outer of the magnetic core samples heat uniformity, but also increases the density of $\alpha-\mathrm{Fe}(\mathrm{Si})$ nucleates, then heat the furnace to $T_{\mathrm{a}}\left(540^{\circ} \mathrm{C}, 550^{\circ} \mathrm{C}, 560^{\circ} \mathrm{C}\right.$, $570^{\circ} \mathrm{C}$, respectively); IV) keep the furnace temperature at each $T_{\mathrm{a}}$ for $60 \mathrm{~min}$, to ensure samples fully crystallization; $\mathrm{V}$ ) cooling to room temperature. It can be seen that $L_{\mathrm{s}}$ of the core is nearly zero without annealing, but significantly improved after annealing. The value of $L_{\mathrm{s}}$ increases with increasing $T_{\mathrm{a}}$ firstly and reaches its maximum of $14.7 \mu \mathrm{H}$ at $T_{\mathrm{a}}=550^{\circ} \mathrm{C}$, then decreases slightly along with increasing $T_{\mathrm{a}}$. Meanwhile, the $H_{c}$ without annealing reaches as high as $10 \mathrm{~A} / \mathrm{m}$, but decreases to $1.1 \mathrm{~A} / \mathrm{m}$ after annealed at $540^{\circ} \mathrm{C}$ for $60 \mathrm{~min}$. When $T_{\mathrm{a}}$ rises to

B

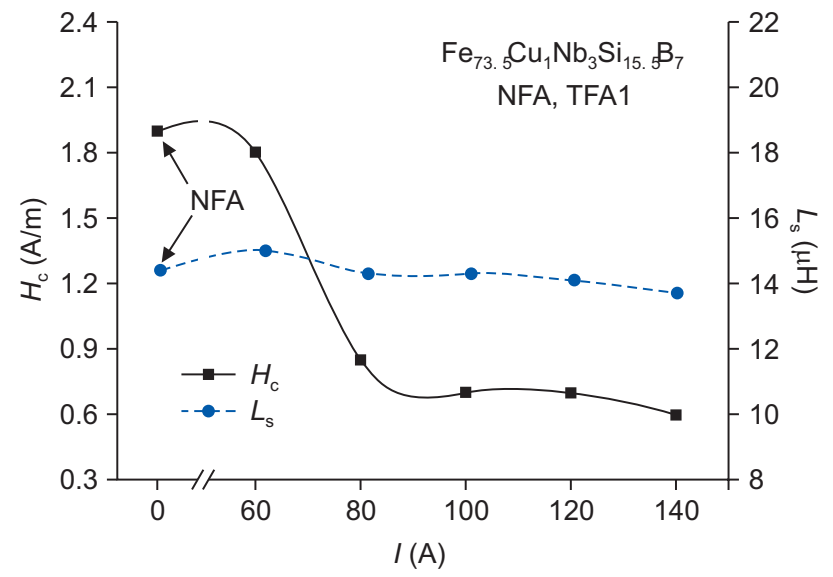

Fig. 3. The dependence of $L_{\mathrm{s}}$ and $H_{\mathrm{c}}$ on (A) four transverse magnetic field annealing (TFA) conditions and (B) TFAl with different current intensity, together with that of no field annealing (NFA) for $\mathrm{Fe}_{73.5} \mathrm{Cu}_{1} \mathrm{Nb}_{3} \mathrm{Si}_{15.5} \mathrm{~B}_{7}$ nanocrystalline magnetic core. The insert in (A) is four TFA annealing conditions named TFAl, TFA2, TFA3, and TFA4, respectively. 
A

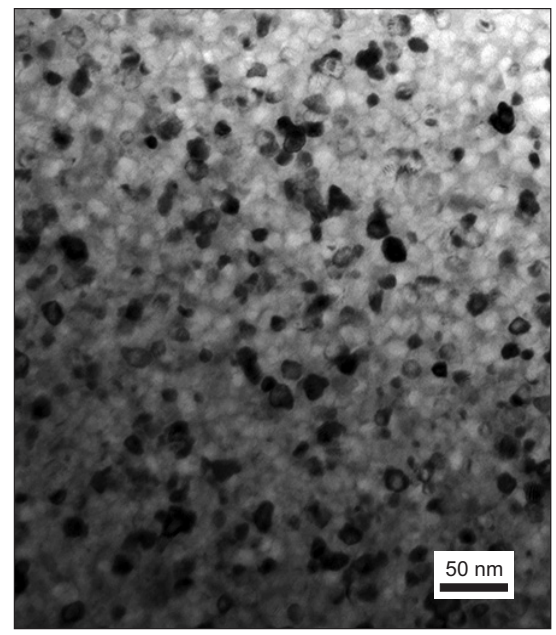

B

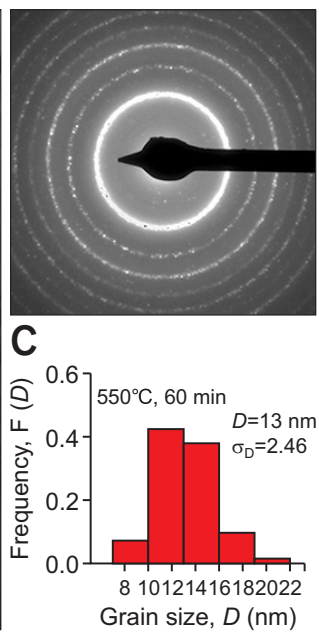

D

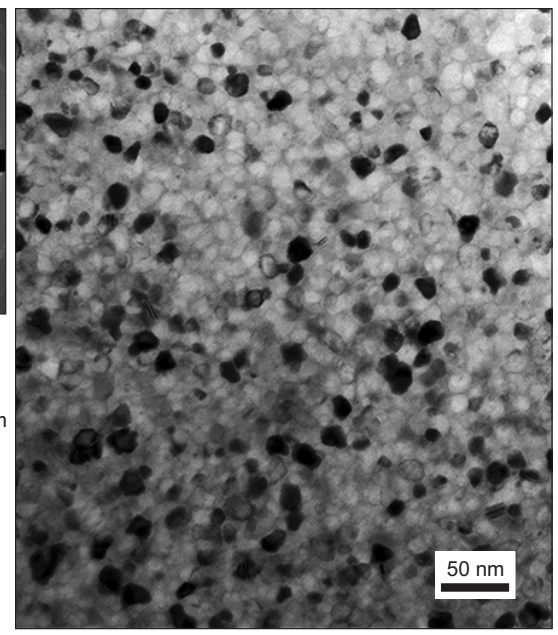

E

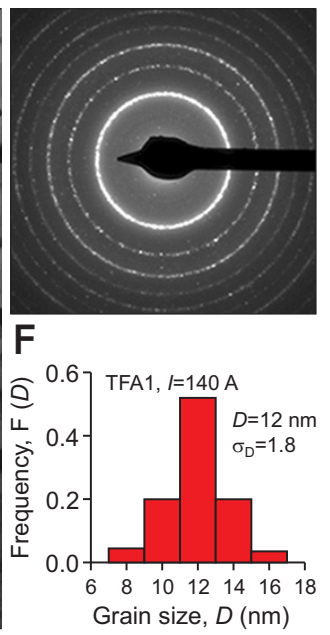

Fig. 4. The bright-field transmission electron microscopy image, selected area electron diffraction pattern and grain size distribution for $\mathrm{Fe}_{73.5} \mathrm{Cu}_{1} \mathrm{Nb}_{3} \mathrm{Si}_{15.5} \mathrm{~B}_{7}$ nanocrystalline magnetic core of (A C): under no field annealing and (D F): under transverse magnetic field annealing 1 (TFA 1 ) with direct current was $140 \mathrm{~A}$.

$550^{\circ} \mathrm{C}, H_{\mathrm{c}}$ increases to $1.9 \mathrm{~A} / \mathrm{m}$. As $T_{\mathrm{a}}$ continues increasing to higher than $560^{\circ} \mathrm{C}, H_{c}$ decreases to nearly $0.8 \mathrm{~A} / \mathrm{m}$.

Considering the nanocrystalline magnetic core used in high frequency requires high $L_{\mathrm{s}}$, the $T_{\mathrm{a}}$ was fixed at $550^{\circ} \mathrm{C}$. But the $H_{c}$ under this annealing condition reached maximum value, so we tried to decrease the coercivity by TFA. Fig. 3A shows the dependence of $L_{\mathrm{s}}$ and $H_{\mathrm{c}}$ of nanocrystalline magnetic core on four TFA conditions, together with that of NFA. The four TFA conditions were carried out by applying transverse magnetic field through different annealing stage, respectively, which named TFA1, TFA2, TFA3, and TFA4 (detail described in the experimental procedures), as shown in the insert in Fig. 3A. The DC intensity in each TFA conditions are all set as $100 \mathrm{~A}$ to ensure a constant magnetic field. According to the results, the $H_{c}$ of sample after NFA is $1.9 \mathrm{~A} / \mathrm{m}$. However, when applied transverse magnetic field, $H_{\mathrm{c}}$ decreases remarkably and exhibits the minimum value of $0.7 \mathrm{~A} / \mathrm{m}$ under TFA1. Meanwhile, $L_{\mathrm{s}}$ almost remains the same value under four TFA conditions. Therefore, the optimum TFA mode is TFA1. To investigate the dependence of $L_{\mathrm{s}}$ and $H_{\mathrm{c}}$ on different magnetic field, we adjusted DC current $(I)$ from $60 \mathrm{~A}$ to 140 A under TFA1. The experimental results are shown in Fig. 3B. Similarly, $L_{\mathrm{s}}$ has a slight fluctuation variation, while $H_{c}$ exhibits sensitive to the current intensity. When $I$ is $60 \mathrm{~A}$, the value of $H_{\mathrm{c}}$ is $1.8 \mathrm{~A} / \mathrm{m}$, just a little lower than that of NFA, which suggests the effect of magnetic field is extremely weak under this condition. As $I$ increases to $80 \mathrm{~A}, H_{\mathrm{c}}$ decreases rapidly to $0.85 \mathrm{~A} / \mathrm{m}$, and then shows a gradually decreasing tendency with increasing current intensity. It is clearly seen that $H_{\mathrm{c}}$ is as low as $0.6 \mathrm{~A} / \mathrm{m}$ when $I$ increases to $140 \mathrm{~A}$. Hence, we find that at TFA 1 condition, the current intensity larger than $80 \mathrm{~A}$ is effective for decreasing the $H_{c}$. The reason is that uniaxial anisotropy $K_{\mathrm{u}}$ induced by transvers field annealing dominates over other anisotropies and reduces the coercivity (Herzer, 1997; Suzuki \& Herzer, 2012). This is the result we are looking for, that is, not only effectively reducing the $H_{\mathfrak{c}}$, but also maintaining the high $L_{s}$.

XRD analyses were performed on $\mathrm{Fe}_{73.5} \mathrm{Cu}_{1} \mathrm{Nb}_{3} \mathrm{Si}_{15.5} \mathrm{~B}_{7}$ nanocrystalline magnetic core samples under NFA condition and TFA1 with different current intensity (results are not shown here). Three characteristic diffraction peaks corresponding to (110), (200), (211) plane, respectively, of $\alpha-\mathrm{Fe}(\mathrm{Si})$ phase can be identified for all the NFA and TFA1 samples and there is almost no obvious difference for each sample from the XRD patterns. The average grain size $(D)$ calculated based on (110) plane with Scherrer's equation was $13 \mathrm{~nm}$ for all NFA and TFA1 samples. To further understand the microstructure, bright-field TEM and selected area electron diffraction (SAED) analyses were carried out on NFA and TFA1 sample ( $I=140 \mathrm{~A})$, as shown in Fig. 4. The grain distributions are quite uniform and the volume fractions of nanocrystals are pretty high, which results in identical ultrafine microstructure feature. The diffraction patterns of these two samples from SAED are almost the same. To acquire accurate description of grain size, statistical analysis was carried out by analyzing more than 200 grains for each sample. It is found that the average grain size of NFA and TFA1 ( $=140 \mathrm{~A}$ ) samples are $13 \mathrm{~nm}$ and $12 \mathrm{~nm}$, which is consistent with XRD results. However, the grain size of NFA sample mainly range in 10 16 $\mathrm{nm}$, while most nanocrystals of TFA1 ( $I=140 \mathrm{~A})$ sample are measured as $12 \mathrm{~nm}$. What is more, the mean square deviation $(\sigma)$ is 1.80 for TFA1 $(I=140 \mathrm{~A})$ sample, which is much smaller than that of NFA sample $\left(\sigma_{\mathrm{NFA}}=2.46\right)$, reflecting a more uniform nanocrystalline structure. Recently, it was found that 
the crystallization reaction rate of Fe-based nanocrystalline (Miglierini et al., 2015; Onodera et al., 2015) is increased by applying extra high magnetic field annealing. It is suggested

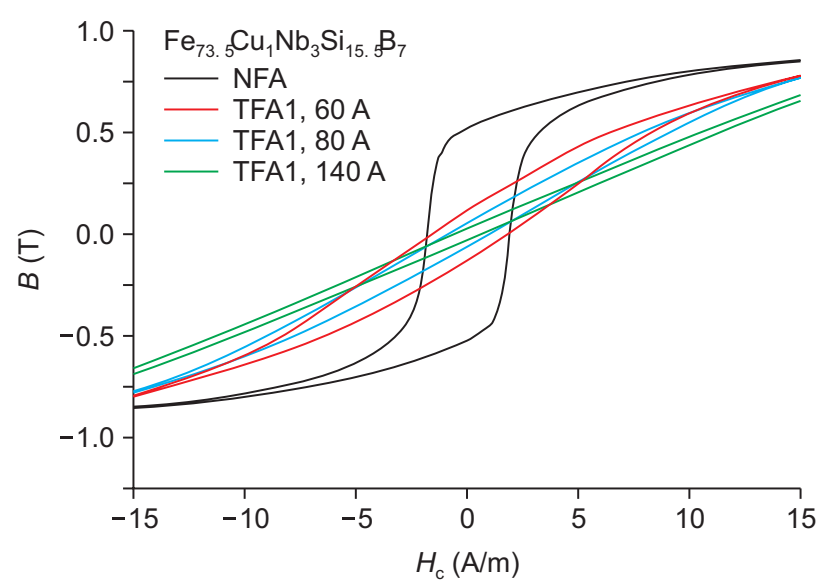

Fig. 5. The characteristics hysteresis loop for $\mathrm{Fe}_{73.5} \mathrm{Cu}_{1} \mathrm{Nb}_{3} \mathrm{Si}_{15.5} \mathrm{~B}_{7}$ nanocrystalline magnetic core under no field annealing (NFA) and transverse magnetic field annealing 1 (TFAl) with direct current were $80 \mathrm{~A}$ and 140 A, respectively.
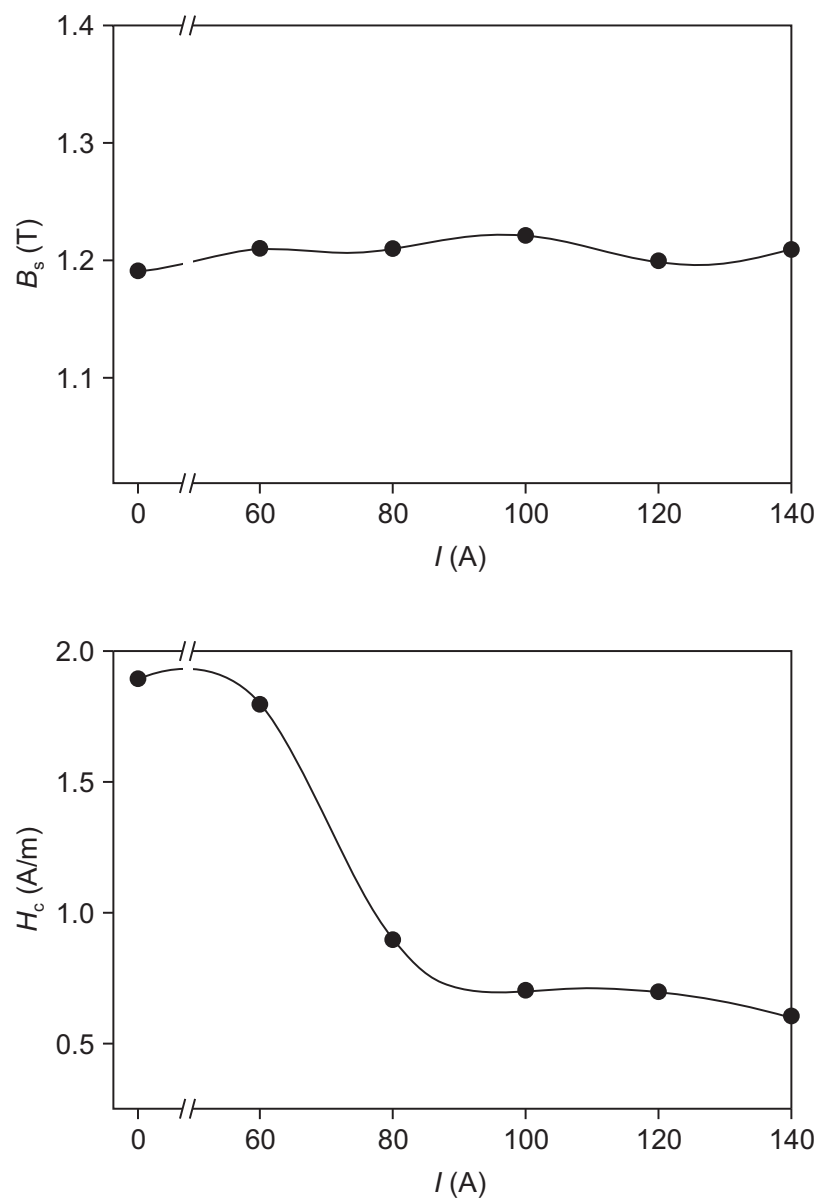

that the nucleation activation energy for primary crystal phase is decreased under field annealing, which results in the increase of nucleation rate and density, whereas the crystallization mechanism is not changed (Fujii et al., 2008; Onodera et al., 2015), so the grain size distribution is more uniform. That is why the mean square deviation of TFA1 ( $I=140 \mathrm{~A})$ sample is less than that of NFA.

Fig. 5 exemplifies the characteristics hysteresis loops under NFA and TFA1 (I=60 A, 80 A, 140 A) conditions. Obviously, flat loops are obtained after TFA and that the bigger current intensity is, the longer and narrower hysteresis loop becomes. Flat loops means lower magnetic remanence ratio and coercivity and more difficult to be saturated with increasing magnetization, indicating the improvement of anti-DC bias properties of nanocrystalline magnetic core products. Fig. 6 summarizes the dependence of specific magnetic properties $\left(B_{s}\right.$, $\mu_{\mathrm{m}}$ and $H_{\mathrm{c}}$ ) and grain size (from XRD result) on DC current intensity $(I)$ for $\mathrm{Fe}_{73.5} \mathrm{Cu}_{1} \mathrm{Nb}_{3} \mathrm{Si}_{15.5} \mathrm{~B}_{7}$ nanocrystalline magnetic core samples. The saturation magnetic flux density $\left(B_{s}\right)$ almost stays invariant with current change. It is reported that $B_{\mathrm{s}}$ can be calculated by equation (Ohta \& Yoshizawa, 2007)
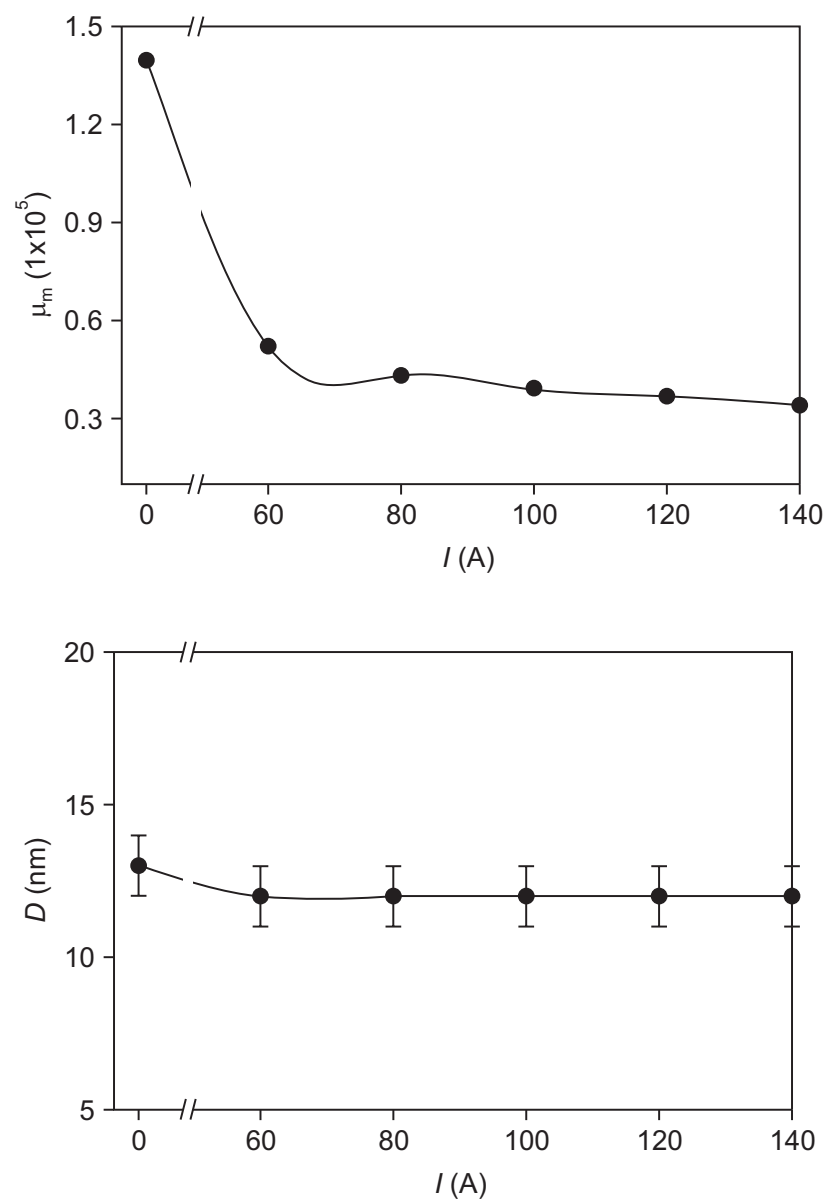

Fig. 6. The dependence of magnetic properties $\left(B_{\mathrm{s}}, \mu_{\mathrm{m}}\right.$ and $\left.H_{\mathrm{c}}\right)$ and grain size $(D)$ on current intensity for $\mathrm{Fe}_{73.5} \mathrm{Cu}_{1} \mathrm{Nb}_{3} \mathrm{Si}_{15.5} \mathrm{~B}_{7}$ nanocrystalline magnetic core. 


$$
B_{\mathrm{s}}=B_{\mathrm{sc}} V_{\mathrm{c}} / V+B_{\mathrm{sa}} V_{\mathrm{a}} / V
$$

where $V_{\mathrm{c}} / V$ and $V_{\mathrm{a}} / V$ stand for the volume fraction of the crystalline phase and the amorphous phase, and $B_{\mathrm{sc}}$ and $B_{\mathrm{sa}}$ are the saturation magnetic flux densities in the crystalline and amorphous phases, respectively. The constant value of $B_{\mathrm{s}}$ indicates magnetic field annealing does not influence the final volume fraction of crystalline phase for any NFA and TFA1 samples.

Meanwhile, the maximum permeability $\left(\mu_{\mathrm{m}}\right)$ and $H_{\mathrm{c}}$ shows similar variation tendency with obvious reduction under TFA conditions and reaches the minimum value of 34,000 and 0.6 $\mathrm{A} / \mathrm{m}$ at $I$ was $140 \mathrm{~A}$, respectively. While $\mu_{\mathrm{m}}$ and $H_{\mathrm{c}}$ shows great decrease with increasing current density from 0 A to $80 \mathrm{~A}$, the mean grain size $\left(D_{\mathrm{m}}\right)$ has no obvious difference which is about $13 \mathrm{~nm}$ for all samples. The result seems to be contrary to the well-known random anisotropy model proposed by Herzer in 1997, 2005, 2013, which suggests that when crystal size is smaller than exchange correlation length $\left(D<<L_{\text {ex }}\right)$, the magneto-crystalline anisotropy $<K_{1}>$ is essentially reduced by exchange interaction. The overall average anisotropy $\langle K\rangle$ is approximated by $<K_{1}>$ and scales down as

$$
<K>=<K_{1}>=\left|K_{1}\right| \cdot x^{2}\left(D / L_{0}\right)^{6}
$$

where $x$ denotes the crystalline volume fraction, $L_{0}$ denotes natural ferromagnetic exchange length and $L_{0} \approx 20 \sim 40 \mathrm{~nm}$ for Fe-based alloys. Since $H_{\mathrm{c}}$ is proportional to $\langle K\rangle$ and permeability $\mu$ is proportional to $\langle K\rangle^{-1}$, hence $H_{c} \propto D^{6}$ while $\mu \propto D^{-6}$. The fact is that the basic anisotropy $\langle K\rangle$ is attributed to the magneto-crystalline anisotropy $K_{1}$, magnetic field induced anisotropies $K_{\mathrm{u}}$ and magneto-elastic anisotropy $K_{\sigma}$. $<K>$ is mainly determined by $K_{1}$ under NFA, and equation (2) is valid only under this condition. However, when transverse

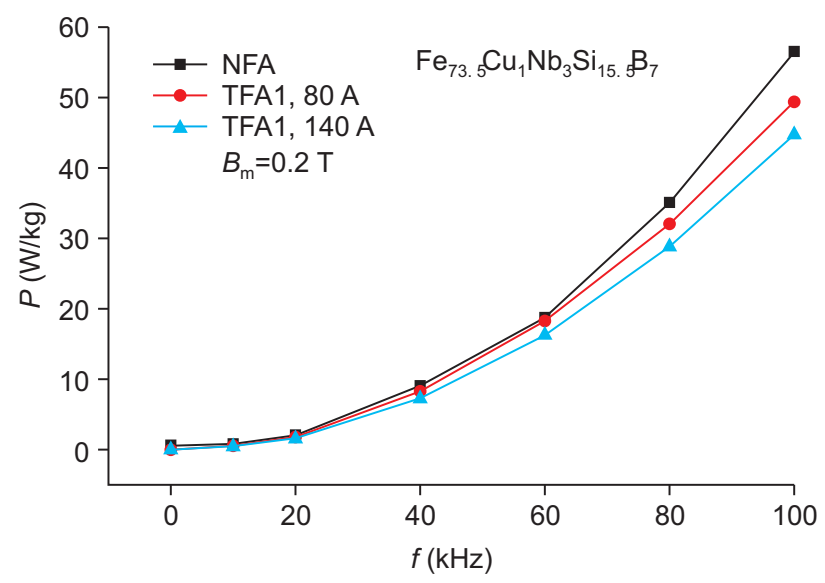

Fig. 7. The dependence of core loss $(P)$ on frequency $(f)$ at $0.2 \mathrm{~T}$ for $\mathrm{Fe}_{73.5} \mathrm{Cu}_{1} \mathrm{Nb}_{3} \mathrm{Si}_{15.5} \mathrm{~B}_{7}$ nanocrystalline magnetic core. NFA, no field annealing; TFAl, transverse magnetic field annealing 1. magnetic field is applied, uniaxial anisotropy $K_{\mathrm{u}}$, induced with axis parallel to the direction of magnetic field, dominates over other anisotropies and wide transverse slab domains are formed, which largely reduce the $H_{\mathrm{c}}$ and $\mu \mathrm{m}$ (Flohrer \& Herzer, 2010; Herzer, 2013; Suzuki \& Herzer, 2012). Herzer also has proved that the major contribution to $H_{c}$ under magnetic field annealing arises from spatial fluctuations of the anisotropy only and the simpler domain configuration (Herzer, 1995). Furthermore, there is a slightly reduction of $H_{\mathrm{c}}$ and $\mu_{\mathrm{m}}$ when the current intensity increases from $80 \mathrm{~A}$ to 140 A, corresponding to the variation of the flat loop as shown in Fig. 6, which indicates that the Hc and $\mu \mathrm{m}$ are closing to the limit value with the increasing magnetic field under TFA1 condition.

Core loss is extremely important for nanocrystalline magnetic core applied for high frequency electronic components. Fig. 7 shows the dependence of core loss $(P)$ on frequency $(f)$ at $0.2 \mathrm{~T}$ for $\mathrm{Fe}_{73.5} \mathrm{Cu}_{1} \mathrm{Nb}_{3} \mathrm{Si}_{15.5} \mathrm{~B}_{7}$ nanocrystalline magnetic core. $P$ increases gradually with increasing $f$. The increasing rate is small when $f \leq 20 \mathrm{kHz}$ but accelerate rapidly after that. However, samples under TFA1 condition show obviously slower increasing tendency and the stronger of current intensity is, the slower tendency is. The core loss for TFA1 ( $I=140 \mathrm{~A}$ ) sample at $20 \mathrm{kHz}$ is $1.6 \mathrm{~W} / \mathrm{kg}$, which is significantly less than that of commercial Finemet alloy of $2.1 \mathrm{~W} / \mathrm{kg}$ (Yoshizawa et al., 1988). The advantage of low core loss at high frequencies such as $80 \mathrm{kHz}$ and $100 \mathrm{kHz}$ compared to those of NFA magnetic core is extremely obvious. Therefore, the combination of high inductance, low core loss, as well as excellent soft magnetic properties promises application of this nanocrystalline magnetic alloy wide application prospect for high frequency transformers of switched power supplies and interface transformers in telecommunication network.

\section{CONCLUSIONS}

Magnetic properties of $\mathrm{Fe}_{73.5} \mathrm{Cu}_{1} \mathrm{Nb}_{3} \mathrm{Si}_{15.5} \mathrm{~B}_{7}$ nanocrystalline magnetic core under NFA and TFA conditions aiming at decreasing the coercivity $\left(H_{c}\right)$ while keeping the high inductance $\left(L_{\mathrm{s}}\right)$ were investigated. The main results are summarized as follows: 1 . $\mathrm{Fe}_{73.5} \mathrm{Cu}_{1} \mathrm{Nb}_{3} \mathrm{Si}_{15.5} \mathrm{~B}_{7}$ nanocrystalline magnetic core annealed with transverse magnetic field applied during the whole annealing process with annealing temperature $550^{\circ} \mathrm{C}$ (TFA1) exhibits the lowest $H_{\mathrm{c}}$ while keeping high $L_{\mathrm{s}}$ compared other annealing conditions. $H_{\mathrm{c}}$ also shows remarkable decrease with increasing DC intensity under TFA1 condition while $L_{\mathrm{s}}$ keeps almost the constant value. 2 . The average grain size and crystallization degree of the nanocrystalline magnetic core under NFA and TFA1 conditions exhibit no obvious difference, but the latter shows a more uniform grain size distribution. 3. Uniaxial anisotropy $K_{\mathrm{u}}$, induced by transverse magnetic field, flattens the hysteresis 
loop greatly and lowers the maximum permeability and coercivity by dominating over other anisotropies. 4 . The nanocrystalline magnetic core under TFA1 with $I=140 \mathrm{~A}$ exhibits high inductance of $13.8 \mu \mathrm{H}$ at $0.3 \mathrm{~V}$ at $100 \mathrm{kHz}$ and excellent magnetic properties with low coercivity of $0.6 \mathrm{~A} /$ $\mathrm{m}$ and low core loss ( $W$ at $20 \mathrm{kHz}$ ) of $1.6 \mathrm{~W} / \mathrm{kg}$ under flux density of $0.2 \mathrm{~T}$.

\section{CONFLICT OF INTEREST}

No potential conflict of interest relevant to this article was reported.

\section{ACKNOWLEDGMENTS}

This work was supported by the National Natural Science Foundation of China (Grant No. 51401052 and 51471050), Key Program of National Natural Science Foundation of China (Grant No. 51631003), the National Key Research and Development Program of China (Grant No. 2016YFB0300500) and Jiangsu Planned Projects for Postdoctoral Research Funds (Grant No. 1302044B).

\section{REFERENCES}

Fan X D, Men H, Ma A B, and Shen B L (2013) Soft magnetic properties in Fe84-xB10C6Cux nanocrystalline alloys. J. Magn. Magn. Mater. 326, $22-27$

Flohrer S and Herzer G (2010) Random and uniform anisotropy in soft magnetic nanocrystalline alloys (invited). J. Magn. Magn. Mater. 322, 1511-1514.

Fujii H, Yardley V A, Matsuzaki T, and Tsurekawa S (2008) Nanocrystallization of $\mathrm{Fe}_{73.5} \mathrm{Si}_{13.5} \mathrm{~B}_{9} \mathrm{Nb}_{3} \mathrm{Cu}_{1}$ soft-magnetic alloy from amorphous precursor in a magnetic field. J. Mater. Sci. 43, 3837-3847.

Herzer G (1990) Grain size dependence of coercivity and permeability in nanocrystalline ferromagnets. IEEE Trans. Magn. 26, 1397-1402.

Herzer G (1992) Nanocrystalline soft magnetic materials. J. Magn. Magn. Mater. 112, 258-262.

Herzer G (1995) Soft magnetic nanocrystalline materials. Scripta Metall. Mater. 33, 1741-1756.

Herzer G (1997) Nanocrystalline soft magnetic alloys. In: Handbook of Magnetic Materials, ed. Buschow K H, pp. 415-462, (Elsevier Science Pub., Amsterdam).

Herzer G (2005) Anisotropies in soft magnetic nanocrystalline alloys. J. Magn. Magn. Mater. 294, 99-106.

Herzer G (2013) Modern soft magnets: amorphous and nanocrystalline materials. Acta. Mater. 67, 718-734.

Hono K, Ping D H, Ohnuma M, and Onodera H (1999) Cu clustering and Si partitioning in the early crystallization stage of an $\mathrm{Fe}_{73.5} \mathrm{Si}_{13.5} \mathrm{~B}_{9} \mathrm{Nb}_{3} \mathrm{Cu}_{1}$ amorphous alloy. Acta Mater. 47, 997-1006.

Ito N, Michels A, Kohlbrecher J, Garitaonandia J S, Suzuki K, and Cashion $J$ D (2007) Effect of magnetic field annealing on the soft magnetic properties of nanocrystalline materials. J. Magn. Magn. Mater. 316, 458-461.

Makino A (2012) Nanocrystalline soft magnetic Fe-Si-B-P-Cu alloys with high B of 1.8-1.9T contributable to energy saving. IEEE Trans. Magn. 48, 1331-1335.
Makino A, Inoue A, and Masumoto T (1995) Nanocrystalline soft magnetic Fe-M-B ( $\mathrm{M}=\mathrm{Zr}, \mathrm{Hf}, \mathrm{Nb}$ ) alloys produced by crystallization of amorphous phase (overview). Mater. Trans. JIM 36, 924-938.

Miglierini M, Procházka V, Rüffer R, and Zbořil R (2015) In situ crystallization of metallic glasses during magnetic field annealing. Acta Mater. 91, 50-56.

Ohta M and Yoshizawa $Y$ (2007) Magnetic properties of nanocrystalline $\mathrm{Fe}_{82.65} \mathrm{Cu}_{1.35} \mathrm{Si}_{x} \mathrm{~B}_{16-\mathrm{x}}$ alloys (x=0-7). Appl. Phys. Lett. 91, 062517.

Ohta $\mathrm{M}$ and Yoshizawa $Y(2008)$ Magnetic properties of high- $B_{\mathrm{s}} \mathrm{Fe}-\mathrm{Cu}-$ Si-B nanocrystalline soft magnetic alloys. J. Magn. Magn. Mater. 320, e750-e753.

Onodera R, Kimura S, Watanabe K, Yokoyama Y, Makino A, and Koyama $\mathrm{K}$ (2015) Nucleation control for fine nano crystallization of Fe-based amorphous alloy by high-magnetic-field annealing. J. Alloy. Compd. 637, 213-218.

Suzuki K and Herzer G (2012) Magnetic-field-induced anisotropies and exchange softening in Fe-rich nanocrystalline soft magnetic alloys. Scripta Mater. 67, 548-553.

Suzuki K, Makino A, Inoue A, and Masumoto T (1991b) Soft magnetic properties of nanocrystalline bcc Fe-Zr-B and Fe-M-B-Cu (M=transition metal) alloys with high saturation magnetization (invited). J. Appl. Phys. 70, 6232-6237.

Suzuki K, Makino A, Kataoka N, Inoue A, and Masumoto T (1991a) High saturation magnetization and soft magnetic properties of bcc Fe-Zr-B and Fe-Zr-B-M ( $\mathrm{M}=$ transition metal) alloys with nanoscale grain size. Mater. Trans. JIM 32, 93-102.

Willard M A, Laughlin D E, and McHenry M E (1998) Structure and magnetic properties of $\left(\mathrm{Fe}_{0.5} \mathrm{Co}_{0.5}\right)_{88} \mathrm{Zr}_{7} \mathrm{~B}_{4} \mathrm{Cu}_{1}$ nanocrystalline alloys. $J$. Appl. Phys. 84, 6773-6777.

Yoshizawa Y, Oguma S, and Yamauchi K (1988) New Fe-based soft magnetic alloys composed of ultrafine grain structure. J. Appl. Phys. 64, 6044-6046.

Yoshizawa Y and Yamauchi K (1990) Fe-based soft magnetic alloys composed of ultrafine grain structure. Mater Trans. JIM 31, 307-314. 